\title{
Pulmonary Hypertension “Out of Proportion” in Patients who are Candidates for Heart Transplant: Does Acute Vasodilator Response to Sildenafil Predict Survival after Transplant?
}

Elvira Barrios Garrido-Lestache ${ }^{1}$, Miguel Angel Gómez- Sánchez ${ }^{1 *}$, Javier de la Cruz Bértolo², Agustin Albarran Gonzalez -Trevilla ${ }^{1}$, Maria Teresa Velázquez Martín', Maria Jose Ruiz Cano', Juan Francisco Delgado Jiménez', Pilar Escribano Subias', Carmen Jiménez LópezGuarch ${ }^{1}$, Maria Angelica Corres Peiretti ${ }^{3}$, Emilio Renes Carreño ${ }^{3}$, David Lora Pablos ${ }^{2}$ and Jose Cortina Romero ${ }^{4}$

${ }^{1}$ Cardiology Department, Hospital Universitario 12 Octubre, Spain

${ }^{2}$ Clinical Research Unit, IMAS12-CIBERESP, Hospital Universitario 12 Octubre, Spain

${ }^{3}$ Postoperative Cardiac Care Unit, Hospital Universitario 12 Octubre, Spain

${ }^{4}$ Cardiac Surgery Department, Hospital Universitario 12 Octubre, Spain

\begin{abstract}
Introduction: The presence Pulmonary Hypertension $(\mathrm{PH})$ in the pre-transplant evaluation period, had an increase in morbidity and mortality following heart transplant, secondary to right ventricular failure; however, in recent years it has been shown that the presence of $\mathrm{PH}$ while still reversible does not appear to be associated with this increase risk. The aim of this work is to study the efficacy and safety of sildenafil in order to evaluate the reversibility of $\mathrm{PH}$ associated with $\mathrm{CHF}$ in heart transplant candidates in relation to the clinical outcome after surgery.

Methods and Results: Included were all heart transplant patients with $\mathrm{PH}$ who had previously undergone an acute vasodilator test and then chronic treatment with sildenafil, and the morbidity and mortality of these patients were compared to those of heart transplant patients without prior PH. Between September 2001 and April 2010, 165 orthotopic transplants were performed, 31 of these patients had out of proportion PH and 134 of them not. Patients with $\mathrm{PH}$ underwent an acute vasodilator test and then chronic treatment with sildenafil. There were no statistically significant differences observed in the subsequent evolution of the $\mathrm{PH}$ group vs. the non-PH group in terms of total mortality ( $22.6 \%$ vs. $24.6 \%$ ), in-hospital mortality (6.5\% vs. $8.2 \%)$, days in ICU (3-7 d vs. $4-7 \mathrm{~d})$, need for vasoactive drugs (1-3 d vs. $1-4$ d), need for counterpulsation balloon pump ( $53.4 \%$ vs. $46.4 \%)$ or need for hemodiafiltration $(4.5 \%$ vs. $7 \%)$
\end{abstract}

Conclusion: In patients with out of proportion $\mathrm{PH}$ associated with $\mathrm{CHF}$ in pre-transplant evaluation, a positive response to the acute vasodilator test with sildenafil predicts mortality and morbidity similar to that of heart transplant patients with no prior $\mathrm{PH}$.

Keywords: Pulmonary hypertension; Heart transplant; Sildenafil

\section{Introduction}

The presence of Pulmonary Hypertension (PH) in patients with Chronic Heart Failure (CHF) referred for heart transplant (HT) evaluation is a relatively frequent occurrence, present in more than $60 \%$ of cases $(1,2)$, and has significant functional, prognostic and therapeutic implications.

The assessment of $\mathrm{PH}$ in patients in cardiac pre-transplant evaluation is currently a controversial point. The pre-operative presence of $\mathrm{PH}$ has long been considered an independent risk factor for premature mortality and heart complications following transplant, mainly secondary to right ventricular failure [1-3] and has come to be considered a relative contraindication for transplant [4]. However, in recent years, several published studies, such as the work of Drako et al. [5], Goland et al. [6] and Gude et al. [7], among others, have shown that the presence of $\mathrm{PH}$ which is reversible after the administration of vasodilator drugs, regardless of its severity, leads to a similar mortality and morbidity of that of heart transplant patients without associated $\mathrm{PH}$. On the other hand, irreversible $\mathrm{PH}$ constitutes one of the principal risk factors for premature mortality and is therefore a contraindication for transplant. The next step would be to establish the cut-off point in the parameters of PH, to wit, Pulmonary Vascular Resistance (PVR) and mean Transpulmonary Gradient (TPG), beyond which the risks of heart transplant would increase significantly. There is currently no consensus in this regard and different cut-off values are used in published work. In 1990, Erickson et al. [8] reviewed the PH parameters in 109 cardiac pre-transplant patients and observed that a TPG greater than or equal to $12 \mathrm{mmHg}$ was associated with a significant increase in mortality at
1, 6 and 12 months after transplant [8]. More recently, Delgado et al. studied 112 with a TPG $>12 \mathrm{mmHg}$ and PVR $>2.5 \mathrm{UW}$ both at baseline and after using vasodilators and demonstrated a significant increase in premature mortality after heart transplant [9].

Among the drugs and protocols used to assess the reversibility of $\mathrm{PH}$ are nitroprusside and nitrates, prostacyclin, prostaglandin E1, nitric oxide and milrinone. All of these have proven to be effective [1014]. However, these drugs in turn pose many limitations themselves, firstly due to their manner of administration, most of which are inhaled or intravenous, and secondly due to adverse effects such as arterial hypotension, migraines, facial flushing and hot flashes. Thus, there is a need to continue investigating new drugs. The objective of this work is to study the efficacy and safety of oral sildenafil in order to evaluate the reversibility of $\mathrm{PH}$ associated with $\mathrm{CHF}$ in patients undergoing cardiac pre-transplant evaluation by way of an acute vasodilator test,

*Corresponding author: Miguel Angel Gómez Sánchez, FESC, Servicio de Cardiología Unidad de Insuficiencia Cardiaca, Trasplante e Hipertensión Pulmonar Hospital Universitario 12 de Octubre Avenida de Córdoba s/n, 28041 Madrid, Spain, Tel/Fax: +34913908669; E-mail: mgomezsanchez@salud.madrid.org

Received January 15, 2013; Accepted April 19, 2013; Published April 22, 2013

Citation: Garrido-Lestache EB, Gómez- Sánchez MA, Cruz Bértolo Jdl, Gonzalez -Trevilla AA, Martín MTV, et al. (2013) Pulmonary Hypertension "Out of Proportion" in Patients who are Candidates for Heart Transplant: Does Acute Vasodilato Response to Sildenafil Predict Survival after Transplant? J Pulmon Resp Med S4: 003. doi:10.4172/2161-105X.S4-003

Copyright: (C) 2013 Garrido-Lestache EB, et al. This is an open-access article distributed under the terms of the Creative Commons Attribution License, which permits unrestricted use, distribution, and reproduction in any medium, provided the original author and source are credited. 
Citation: Garrido-Lestache EB, Gómez- Sánchez MA, Cruz Bértolo Jdl, Gonzalez -Trevilla AA, Martín MTV, et al. (2013) Pulmonary Hypertension "Out of Proportion" in Patients who are Candidates for Heart Transplant: Does Acute Vasodilator Response to Sildenafil Predict Survival after Transplant? J Pulmon Resp Med S4: 003. doi:10.4172/2161-105X.S4-003

and compare mortality and post-transplant evolution between the patient group with reversible $\mathrm{PH}$ and heart transplant patients without $\mathrm{PH}$, over the same period of time post-transplant.

\section{Methods}

This is a retrospective study. Between September 2001 and April 2010, 165 orthotopic heart transplants, excluding retransplants, were performed in our transplant program. After optimization of the medical treatment for $\mathrm{CHF}$, at the maximum tolerated doses, these were in turn divided into two groups based on the values obtained in the right catheterization performed as part of the pre-transplant evaluation protocol. The "PH" group consisted of heart transplant patients with out of proportion $\mathrm{PH}$, defined as the presence of values for mean pulmonary artery pressure $(\mathrm{mPAP})>25 \mathrm{mmHg}$, TPG $>12 \mathrm{mmHg}$ and PVR $>3$ UW, the patient had to have the three values, on all of whom the acute vasodilator test was performed. The "non-PH" group consisted of heart transplant patients without $\mathrm{PH}$ or with $\mathrm{PH}$ that was slight and in no case disproportionate.

The study was conducted in compliance with the investigator's Institutional Review Board/Independent Ethics Committee (IRB/IEC). The study was conducted in full compliance with the Declaration of Helsinki. The written informed consent was obtained before the subject completed any screening procedures and before the administration of study medication.

\section{Right catheterization}

Prior to right catheterization, patients had to undergo optimal medical treatment for $\mathrm{CHF}$ and, for greater optimization of left ventricular function; all patients were treated with vasoactive drugs and dobutamine between 5 and 10 micrograms/kilogram/minute, for at least 48 hours prior to the hemodynamic study.

Basal right catheterization: This was performed using a Swan-Ganz thermodilution catheter and the following hemodynamic parameters were recorded: mean Pulmonary Artery Pressure (mPAP), systolic Pulmonary Artery Pressure (sPAP), Pulmonary Vascular Resistance (PVR), Transpulmonary Gradient (TPG), Pulmonary Wedge Pressure (PWP), thermodilution Cardiac Output (CO), Right Atrium Pressure (RAP), Arterial Oxygen Saturation ( $\mathrm{SaO} 2)$ and mixed Venous Oxygen Saturation (SvO2). At the same time, Mean Systemic Arterial Pressure (MAP) and Systemic Vascular Resistance (SVR) were measured.

Acute vasodilator test: An acute vasodilator test was performed systematically, and in the absence of treatment with nitrates or nitroglycerin, on all patients with out of proportion $\mathrm{PH}$, by administering $100 \mathrm{mg}$ of oral sildenafil and repeating the measurement at 15, 30 and 45 minutes, monitoring adverse effects. The positive response criteria in acute vasodilation test TPG under $12 \mathrm{mmHg}$ plus a PVR under $3 \mathrm{UW}$ and without sistolic blood pressure less than $85 \mathrm{mmHg}$ or fall in cardiac output [11].

\section{Post-transplant clinical events}

In cardiac post-transplant follow up on both groups, total, inhospital and out-of-hospital mortality and morbidity were analyzed, in terms of: days stayed in the post-operative care unit, days using vasoactive drugs, days on invasive mechanical ventilation, need for hemodynamic support using a intra-aortic counterpulsation balloon pump in post-op and need for hemofiltration.

\section{Statistical methods}

The information from qualitative variables with their absolute and relative frequency distributions (percentage) was summarized in the descriptive analysis. Quantitative variables were described by measuring mean or median central tendency, and measurements of dispersion, standard deviation or interquartile range, respectively.

Comparison of the distribution of baseline and post-transplant characteristics between the two study groups was performed, for qualitative variables, using the chi-square test or Fisher's exact test, and for the quantitative variables, using the Student's t-test, or, in case of non normal distributions, using a non-parametric test.

The evolution of the hemodynamic parameters over time was evaluated using procedures of analysis of variance for repeated measurements and graphic representation.

The probability of survival function was plotted for each of the two study groups using the Kaplan-Meier method. The number of subjects at risk at the start of each follow-up year was estimated using the actuarial method. The differences between the survival distributions of the $\mathrm{PH}$ and non- $\mathrm{PH}$ groups were evaluated using the log-rank test. The data analysis for this paper was generated using SAS software, SAS Institute Inc., Cary, NC, USA.

\section{Results}

\section{Baseline characteristics}

Between September 2001 and April 2010 a total of 165 orthotopic

\begin{tabular}{|c|c|c|c|}
\hline & $\begin{array}{l}\text { PH Group } \\
\qquad \mathrm{N}=31\end{array}$ & $\begin{array}{l}\text { Non-PH Group } \\
\qquad \mathrm{N}=134\end{array}$ & $\mathbf{P}$ \\
\hline $\begin{array}{l}\text { Age, years } \\
\text { Males } \\
\text { Etiology } \\
\text { Coronary disease } \\
\text { Idiopathic dilated } \\
\text { Other } \\
\text { Urgency } \\
\text { Urgent } \\
\text { Elective } \\
\text { Unknown }\end{array}$ & $\begin{array}{c}51.4(23-65) \\
25(80.7 \%) \\
12(38.7 \%) \\
7(22.6 \%) \\
12(38.7 \%) \\
5(16.1 \%) \\
24(77.4 \% \\
2(6.5 \%)\end{array}$ & $\begin{array}{l}38(28.4 \%) \\
52(39.8 \%) \\
44(32.8 \%)\end{array}$ & $\begin{array}{l}0.68 \\
0.56 \\
0.19\end{array}$ \\
\hline $\begin{array}{l}\text { Treatment } \\
\text { Beta blockers } \\
\text { ACEi/ARB II } \\
\text { Spironolactone } \\
\text { Digoxin } \\
\text { Diuretics }\end{array}$ & $\begin{array}{c}13(42 \%) \\
20(64 \%) \\
18(58.1 \%) \\
18(58.1 \%) \\
27(87.1 \%)\end{array}$ & $\begin{array}{c}53(40 \%) \\
79(59 \%) \\
74(55.2 \%) \\
55(41 \%) \\
114(85 \%)\end{array}$ & $\begin{array}{l}0.81 \\
0.75 \\
0.44 \\
0.20 \\
1.00\end{array}$ \\
\hline $\begin{array}{l}\text { Hemodynamic parameters } \\
\text { mPAP } \\
\text { sPAP } \\
\text { dPAP } \\
\text { PWP } \\
\text { RAP } \\
\text { CO } \\
\text { PVR } \\
\text { TPG }\end{array}$ & $\begin{array}{c}43.8 \pm 8.8 \\
66.4 \pm 13.5 \\
29.7 \pm 7.7 \\
23 \pm 7.7 \\
8.8 \pm 5.5 \\
3.7 \pm 1.4 \\
6.1 \pm 2.6 \\
20.3 \pm 4.4\end{array}$ & $\begin{array}{c}28.2 \pm 8.9 \\
41 \pm 13.2 \\
20 \pm 11 \\
20.7 \pm 8.6 \\
10.2 \pm 7.5 \\
3.5 \pm 1.2 \\
2.4 \pm 1.5 \\
7.4 \pm 4\end{array}$ & $\begin{array}{c}0.001 \\
0.001 \\
<0.001 \\
0.27 \\
0.66 \\
0.63 \\
0.001 \\
0.001\end{array}$ \\
\hline
\end{tabular}

"PH" group (pre-transplant disproportionate $\mathrm{PH}$ ); "non-PH" group (pre-transplant absence of or slight $\mathrm{PH}$ ); mPAP: mean pulmonary artery pressure $\mathrm{mmHg}$; sPAP systolic pulmonary artery pressure $\mathrm{mmHg}$; PVR: pulmonary vascular resistances $\mathrm{mmHg}$; TPG: transpulmonary gradient; PWP: pulmonary wedge pressure $\mathrm{mmHg}$; $\mathrm{CO}$ : cardiac output I/min; RAP: right atrium pressure $\mathrm{mmHg}$; SaO2; arterial oxygen saturation; SvO2: mixed venous oxygen saturation. Age is expressed in terms of median and interquartile range; sex, etiology and treatment in form of frequency and percentage; hemodynamic parameters in means and standard deviations.

Table 1: Clinical and hemodynamic characteristics of patients in baseline condition. 
Citation: Garrido-Lestache EB, Gómez- Sánchez MA, Cruz Bértolo Jdl, Gonzalez -Trevilla AA, Martín MTV, et al. (2013) Pulmonary Hypertension "Out of Proportion" in Patients who are Candidates for Heart Transplant: Does Acute Vasodilator Response to Sildenafil Predict Survival after Transplant? J Pulmon Resp Med S4: 003. doi:10.4172/2161-105X.S4-003

heart transplant patients, of which 31 belonged to the "PH" group and 134 to the "non-PH" group, were included. Both groups were homogeneous in all baseline characteristics except in the hemodynamic pulmonary hypertension measurement parameters, as shown on Table 1.

\section{Acute vasoreactivity test}

Over that period of time, 40 acute vasoreactivity tests were performed following the oral administration of $100 \mathrm{mg}$ of sildenafil, 31 of these patients were transplanted, 3 died while on the waiting list, 3 were still on the list, it was not effective in 2 of them and in 1 of them it was effective; however, the patient was rejected for transplant for not complying with treatment (Figure 1). A significant change in the hemodynamic profile of the 31 patients in the " $\mathrm{PH}$ " group was observed, as shown on Table 2 and in the tendency curves of Figures $2 a$ and $2 b$. Although a significant, overall tendency toward a decrease in PVR, TPG and mPAP was observed, among patients who were transplanted only 19 of the $31(61,3 \%)$ achieved a TPG $<12 \mathrm{mmHg}$ and PVR $<3$ UW at the end of the test, however the remaining 12 transplants patients achieved a TPG $<16$ and PVR $<3$ (Table 3). A decrease in PVR of 50.6 $+/-13.7 \%$ and a decrease in SVR of $21+/-17.1 \%$ were observed. A significant increase in CO by $15.6 \%$ and decrease in PCP by $18.6 \%$ were also observed.

In the two patients in whom it was not effective, the use of prostanoids was not effective.

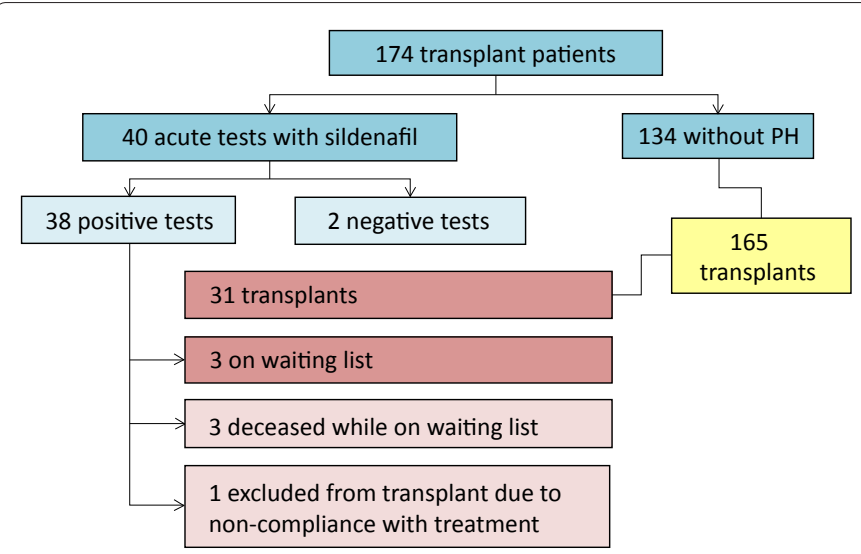

Figure 1: Distribution of patients who were heart transplant candidates between September 2001 and April 2010

\begin{tabular}{|l|c|c|c|c|c|}
\hline & Baseline & $\mathbf{1 5} \mathbf{~}$ & $\mathbf{3 0} \mathbf{~}$ & Max & $\mathbf{p}$ \\
\hline sPAP & $66.4 \pm 13.5$ & $59.9 \pm 15.4$ & $53.3 \pm 12.3$ & $48.4 \pm 13.7$ & 0.002 \\
\hline dPAP & $29.7 \pm 7.7$ & $25.8 \pm 7.5$ & $23.4 \pm 6.6$ & $20.3 \pm 6.5$ & 0.005 \\
\hline mPAP & $43.8 \pm 8.8$ & $39.5 \pm 9.7$ & $35 \pm 8.5$ & $31.3 \pm 8.7$ & $<0.001$ \\
\hline TPG & $20.3 \pm 4.4$ & $16.4 \pm 5.8$ & $13.8 \pm 4.6$ & $11.5 \pm 3.5$ & $<0.001$ \\
\hline PRV & $6.1 \pm 2.6$ & $4.4 \pm 2.4$ & $3.7 \pm 1.8$ & $3 \pm 1.4$ & 0.001 \\
\hline PWP & $23 \pm 7.7$ & $21.5 \pm 7.7$ & $20.8 \pm 7.7$ & $20.1 \pm 7.3$ & 0.56 \\
\hline CO & $3.7 \pm 1.4$ & $4.4 \pm 1.2$ & $4.2 \pm 1.2$ & $4.5 \pm 1.4$ & 0.005 \\
\hline MBP & $68,5 \pm 34$ & & & $57.8 \pm 34$ & 0.003 \\
\hline SvO2 & $57 \pm 10.9$ & $58 \pm 10.2$ & $61.1 \pm 7.7$ & $63 \pm 8.4$ & 0.08 \\
\hline
\end{tabular}

Table 2: Evolution of the different hemodynamic parameters measured during the acute vasodilator test with sildenafil in the "PH" group; baseline and at 15, 30 and 45 minutes (considered the maximum effect); sPAP: systolic pulmonary artery pressure $\mathrm{mmHg}$; dPAP: diastolic pulmonary artery pressure mmHg; mPAP: mean pulmonary artery pressure $\mathrm{mmHg}$; TPG: transpulmonary gradient; PVR: pulmonary vascular resistances WU, PWP: pulmonary wedge pressure $\mathrm{mmHg}$; $\mathrm{CO}$ : cardiac output I/min; MBP: Mean blood pressure $\mathrm{mmHg}$; SvO2: mixed venous oxygen saturation.
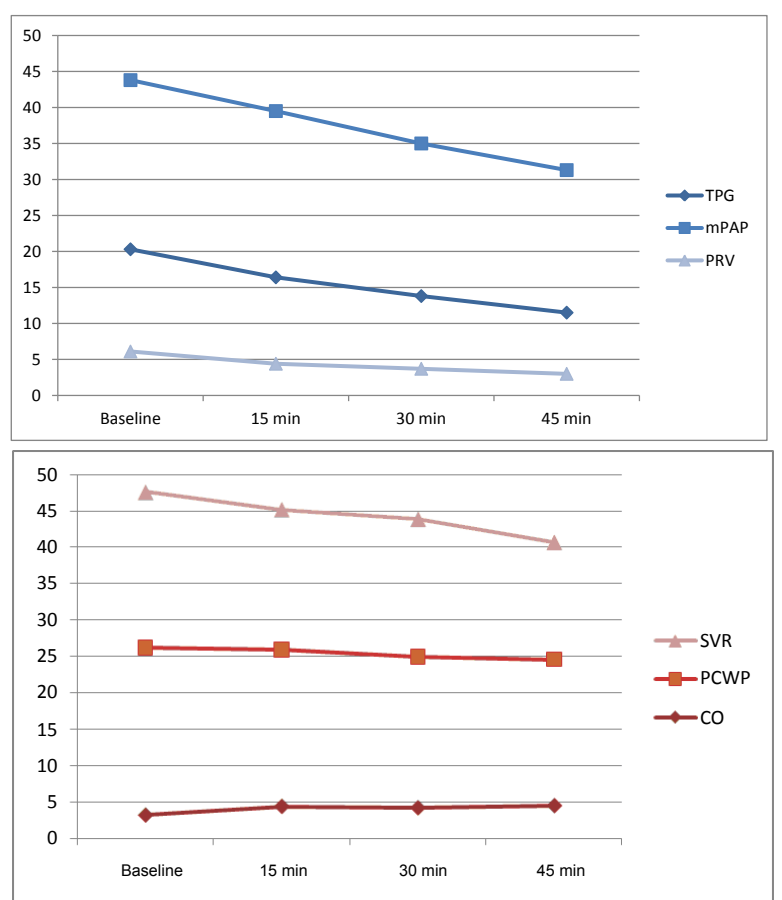

Figures 2: $\mathbf{a}$ and b: Tendency curve of the mean hemodynamic parameters during the acute vasodilator test with sildenafil; mPAP: mean pulmonary artery pressure $\mathrm{mmHg}$, TPG: transpulmonary gradient $\mathrm{mmHg}$, PVR: pulmonary vascular resistances WU, PCWP: pulmonary capillary wedge pressure $\mathrm{mmHg}$; CO: cardiac output I/min; SVR: systemic vascular resistances WU

\section{Side effects}

During the procedure, 2 episodes of migraines and 4 of facial flushing were documented. The significant decrease in systemic arterial pressure was asymptomatic.

\section{Immediate post-transplant evaluation}

No statistically significant differences were observed in terms of morbidity: days stayed in ICU, days on mechanical ventilation, need for vasoactive drugs, need for counterpulsation balloon pump or need for hemodiafiltration (Table 4).

\section{Mortality following transplant}

No statistically significant differences were observed in terms of total mortality ("PH” group: 7/31 (22.6\%); "non- $\mathrm{PH}$ " group: 33/134 (24.6\%), p=0.81), in-hospital ("PH" group: $2 / 31$ (6.5\%); "non- $\mathrm{PH}$ group: $11 / 134(8.2 \%), p=0.74)$. Figure 3 shows the Kaplan-Meier survival curves for total mortality in long-term follow up.

\section{Discussion}

The principal findings of our study are that: 1) In patients with out of proportion $\mathrm{PH}$ associated with $\mathrm{CHF}$, the acute vasodilator test with 100 $\mathrm{mg}$ of oral sildenafil is effective in the identification of patients in whom $\mathrm{PH}$ is still reversible. 2) Patients with out of proportion PH associated with CHF who still demonstrate reversibility have similar mortality and morbidity after a heart transplant to that of patients without prior $\mathrm{PH}$.

Among the prognostic factors prior to heart transplant, $\mathrm{PH}$ is considered one of the most significant risk factors. The presence of out of proportion $\mathrm{PH}$ prior to heart transplant signifies a significant increase in mortality and morbidity and thus, a relative contraindication $[3,9]$. However, this is not so clear in the case of $\mathrm{PH}$ which is still in a reversible 
Citation: Garrido-Lestache EB, Gómez- Sánchez MA, Cruz Bértolo Jdl, Gonzalez -Trevilla AA, Martín MTV, et al. (2013) Pulmonary Hypertension "Out of Proportion" in Patients who are Candidates for Heart Transplant: Does Acute Vasodilator Response to Sildenafil Predict Survival after Transplant? J Pulmon Resp Med S4: 003. doi:10.4172/2161-105X.S4-003

phase. Through retrospective analysis, several works have demonstrated that the presence of reversible $\mathrm{PH}$, regardless of its severity, displays a survival rate similar to that of patients with no $\mathrm{PH}$ prior to transplant [57], although this continues to be a controversial subject today. Among the therapeutic options currently available for assessing the reversibility of $\mathrm{PH}$ are arterial vasodilator drugs; nitroprusside, prostacyclin, prostaglandin E1, nitric oxide and milrinone have being used to date. In the event of non-response, the need for cardiac resynchronization or means of left ventricular mechanical support (counterpulsation balloon vs. ventricular assistance) is assessed as the better LV function could improve pulmonary pressure.

The beneficial effects of sildenafil on $\mathrm{PH}$ have already been proven in numerous bodies of work, among these the study with the greatest relevance is the SUPER-1 [15], in which it was concluded

\begin{tabular}{|c|c|c|c|c|}
\hline & TPGbasal & PVRbasal & TPGmax & PVRmax \\
\hline 1 & 22 & 5,6 & 12 & 3,0 \\
\hline 2 & 17 & 1,9 & 10 & 1,1 \\
\hline 3 & 25 & 5,3 & 16 & 2,5 \\
\hline 4 & 21 & 4,5 & 12 & 2,4 \\
\hline 5 & 22 & 8,5 & 15 & 5,0 \\
\hline 6 & 17 & 4,9 & 8 & 2,4 \\
\hline 7 & 19 & 4,6 & 14 & 2,5 \\
\hline 8 & 21 & 7,5 & 13 & 2,9 \\
\hline 9 & 17 & 7,4 & 12 & 3,9 \\
\hline 10 & 17 & 5,0 & 6 & 1,9 \\
\hline 11 & 19 & 3,7 & 9 & 1,7 \\
\hline 12 & 32 & 13,3 & 13 & 3,5 \\
\hline 13 & 20 & 6,5 & 11 & 3,8 \\
\hline 14 & 31 & 14,1 & 13 & 3,7 \\
\hline 15 & 21 & 6,2 & 14 & 3,7 \\
\hline 16 & 17 & 5,0 & 13 & 3,6 \\
\hline 17 & 19 & 6,6 & 10 & 2,5 \\
\hline 18 & 16 & 7,0 & 10 & 3,0 \\
\hline 19 & 19 & 4,5 & 8 & 1,5 \\
\hline 20 & 19 & 4,1 & 11 & 2,1 \\
\hline 21 & 24 & 6,9 & 9 & 2,4 \\
\hline 22 & 22 & 6,1 & 11 & 2,4 \\
\hline 23 & 17 & 3,8 & 14 & 3,0 \\
\hline 24 & 15 & 6,0 & 10 & 2,0 \\
\hline 25 & 30 & 10,7 & 9 & 2,7 \\
\hline 26 & 17 & 5,7 & 12 & 4,1 \\
\hline 27 & 22 & 5,2 & 11 & 2,1 \\
\hline 28 & 16 & 3,2 & 8 & 1,4 \\
\hline 29 & 26 & 6,2 & 7 & 1,6 \\
\hline 30 & 20 & 6,7 & 8 & 1,5 \\
\hline \multirow[t]{2}{*}{31} & 21 & 5,7 & 12 & 2,4 \\
\hline & $20,5(\mathrm{SD}=4,5)$ & $6,3(\mathrm{SD}=2,6)$ & $11(\mathrm{SD}=2,5)$ & $2,6(\mathrm{SD}=0,9)$ \\
\hline
\end{tabular}

Table 3: Evolution of the different hemodynamic parameters measured during the acute vasodilator test with sildenafil in transplant patients with $\mathrm{PH}$; baseline and the maximum effect; TPG: transpulmonary gradient; PVR: pulmonary vascular resistances WU.

\begin{tabular}{|l|c|c|c|}
\hline & $\begin{array}{c}\text { "PH" GROUP } \\
\text { N= 31 }\end{array}$ & $\begin{array}{c}\text { "non-PH" GROUP } \\
\text { N=134 }\end{array}$ & $\mathbf{p}$ \\
\hline Days in ICU & $6(4-7)$ & $5(3-7)$ & 0.37 \\
\hline Days on vasoactive drugs & $2(1-4)$ & $2(1-3)$ & 0.22 \\
\hline $\begin{array}{l}\text { Need for intra-aortic counterpulsation } \\
\text { balloon pump }\end{array}$ & $46.4 \%$ & $53.4 \%$ & 0.35 \\
\hline Need for hemodiafiltration & $7 \%$ & $4.5 \%$ & 0.62 \\
\hline
\end{tabular}

Table 4: Immediate morbidity in cardiac post-transplant patients in both groups.

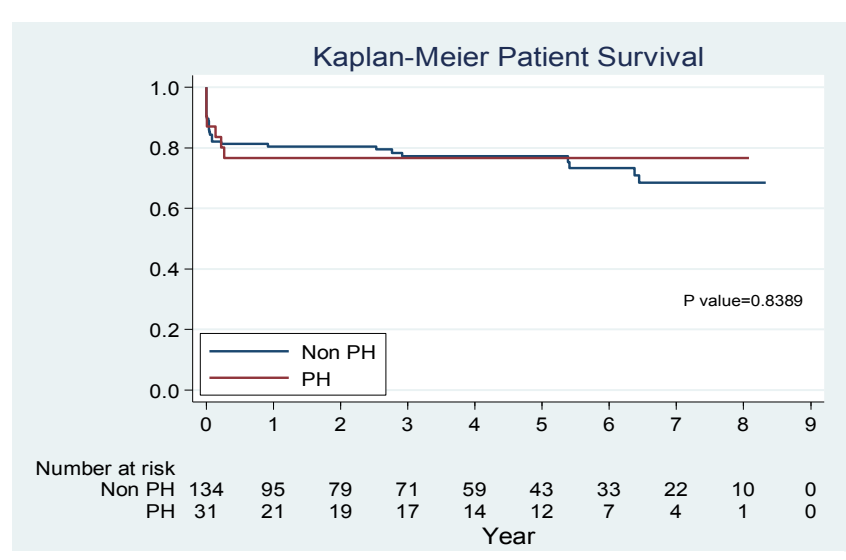

Figure 3: Kaplan-Meier survival curve for total mortality.

that sildenafil improved the capacity for exercise, functional class and hemodynamic parameters in patients with symptomatic pulmonary arterial hypertension, with minimal side effects. Most of these studies included patients with idiopathic pulmonary arterial hypertension associated with congenital heart disease, collagen diseases, chronic thromboembolism, HIV, etc. However, those which study the efficacy of sildenafil in patients with $\mathrm{PH}$ associated with advanced heart failure are few and always have a small sample size. The first work published on heart transplant patients was that of Gómez Sánchez et al. [16], who demonstrated that, in 7 patients on a waiting list for heart transplant, the sublingual administration of $100 \mathrm{mg}$ sildenafil during right catheterization, in other words, performing an acute vasodilator test with sildenafil, allowed for the identification of patients with reversible $\mathrm{PH}$, with significant decreases in mPAP, PVR and mean TPG, no significant variations in SVR, mean systemic AP and no other side effects during its administration. Later would be published the works of Kwang et al. [17], who studied the effect of oral sildenafil administered 10 minutes prior to the induction of anesthesia on patients subjected to valvular surgery, and, at 30 minutes, a significant decrease in mPAP, sPAP and PVR was observed in comparison with a placebo. The works of Jabbour et al. [18] and Zakliczynski et al. [19] on the efficacy and safety of chronic treatment with sildenafil in patients with $\mathrm{PH}$, showed that after several months of treatment with sildenafil, a significant improvement in the hemodynamic parameters was observed, allowing more than $50 \%$ of the cases to be included on the waiting list for heart transplant. In both studies, the treatment was well-tolerated and therapy did not have to be suspended in any of the patients. Finally, this study, with a larger sample size than in previous studies and a control group, demonstrates for the first time that the reversibility identified in the acute vasodilator test with sildenafil has a positive impact on the clinical evolution of transplant patients.

Sildenafil is a potent inhibitor of phosphodiesterase 5, an enzyme involved in the catabolism of cyclic Guanosine Monophosphate (cGMP), which is involved in the Nitric Oxide (NO) cycle. The effects of this drug are already known as a treatment for erectile dysfunctions due to its presence in the corpora cavernosa and its effects on certain cardiovascular pathologies are increasingly becoming apparent as its presence in the lungs and myocardium, with a significant upregulation of the number of receptor in certain pathological circumstances, such as pulmonary hypertension [20] and ventricular hypertrophy [21,22], has been demonstrated. This may explain the acute effect of sildenafil on pulmonary vascular resistances and may justify the positive effect on ventricular function after chronic administration in our patients, although no serial studies on right ventricular function have been 
Citation: Garrido-Lestache EB, Gómez- Sánchez MA, Cruz Bértolo Jdl, Gonzalez -Trevilla AA, Martín MTV, et al. (2013) Pulmonary Hypertension "Out of Proportion" in Patients who are Candidates for Heart Transplant: Does Acute Vasodilator Response to Sildenafil Predict Survival after Transplant? J Pulmon Resp Med S4: 003. doi:10.4172/2161-105X.S4-003

performed in order to confirm this hypothesis. An increase in $\mathrm{CO}$ in the acute study is evident, which on the other hand may be justified by its effect, to a lesser degree, on systemic vascular resistances. Finally, anatomopathological studies of the transplant patients included in our series, who died of a non-cardiac cause, showed that pulmonary vascular lesions correspond to intimal fibrosis and hypertrophy of the middle layer, which are reversible over time [23].

The primary limitations of our study are mainly associated with methodology, as this is a single-center study with retrospective analysis of the variables, to the extent that a small percentage were lost from the databases. Only patients with $\mathrm{PH}$ who received a transplant during this time period were included; therefore, the majority of $\mathrm{PH}$ patients, who are not transplant candidates, were not included. It is not a study controlled with a placebo or with other drugs that have proven effective, and the patients in the study were pre-medicated with dobutamine, which increases cardiac output and lowers pulmonary vascular resistances due to its positive inotropic effect, therefore, we cannot know what the effect of sildenafil would be without dobutamine. Given these limitations, additional prospective, controlled studies must be designed in order to support the results obtained.

In conclusion, it can be suggested that sildenafil is a safe and effective drug when identifying the reversibility of out of proportion $\mathrm{PH}$ in patients who are candidates for heart transplant. This favorable response predicts a clinical evolution, in terms of long-term morbiditymortality, in this group of patients, similar to that of heart transplant patients with no prior PH. Although further studies are needed, prospective, multicenter, with controls and compared with other pulmonary vasodilators to confirm these findings.

\section{Acknowledgements}

Data analysis and the preparation of the manuscript were possible thanks to an unconditional research grant from Pfizer Spain. Authors wish also to thank Silvia Martínez for her contribution in submitting the manuscript to the journal.

\section{Funding}

This work was supported by Pfizer [WS687558]

\section{References}

1. Bonderman D, Martischnig AM, Moertl D, Lang IM (2009) Pulmonary hypertension in chronic heart failure. Int J Clin Pract Suppl : 4-10.

2. Guglin M, Khan H (2010) Pulmonary hypertension in heart failure. J Card Fail 16: $461-474$

3. Christie JD, Edwards LB, Kucheryavaya AY, Aurora P, Dobbels F, et al. (2010) The Registry of the International Society for Heart and Lung Transplantation: twenty-seventh official adult lung and heart-lung transplant report--2010. J Heart Lung Transplant 29: 1104-1118.

4. Mehra MR, Kobashigawa J, Starling R, Russell S, Uber PA, et al. (2006) Listing criteria for heart transplantation: International Society for Heart and Lung Transplantation guidelines for the care of cardiac transplant candidates--2006. J Heart Lung Transplant 25: 1024-1042.

5. Drakos SG, Kfoury AG, Gilbert EM, Horne BD, Long JW, et al. (2007) Effect of reversible pulmonary hypertension on outcomes after heart transplantation. $\mathrm{J}$ Heart Lung Transplant 26: 319-323.

6. Goland S, Czer LS, Kass RM, De Robertis MA, Mirocha J, et al. (2007) Preexisting pulmonary hypertension in patients with end-stage heart failure: impact on clinical outcome and hemodynamic follow-up after orthotopic heart transplantation. J Heart Lung Transplant 26: 312-318.

7. Gude E, Simonsen S, Geiran OR, Fiane AE, Gullestad L, et al. (2010) Pulmonary hypertension in heart transplantation: discrepant prognostic impact of preoperative compared with 1-year post-operative right heart hemodynamics. $J$ Heart Lung Transplant 29: 216-223

8. Erickson KW, Costanzo-Nordin MR, O'Sullivan EJ, Johnson MR, Zucker MJ, et al. (1990) Influence of preoperative transpulmonary gradient on late mortality after orthotopic heart transplantation. J Heart Transplant 9: 526-537.
9. Delgado JF, Gómez-Sánchez MA, Sáenz de la Calzada C, Sánchez V, Escribano P, et al. (2001) Impact of mild pulmonary hypertension on mortality and pulmonary artery pressure profile after heart transplantation. J Heart Lung Transplant 20: 942-948.

10. Torres Macho J, Delgado Jimenez JF, Sanz Salvo J, Gonzalez Mansilla A Sanchez Sanchez V, et al. (2009) Effect of different pharmacologic agents to reverse severe pulmonary hypertension among end-stage heart failure patients. Transplant Proc 41: 2477-2479.

11. Costard-Jäckle A, Fowler MB (1992) Influence of Preoperative Pulmonary Artery Pressure on mortality after Heart Transplantation: Testing of potentia reversibility of Pulmonary Hypertension with Nitroprusside is useful in defining a high Risk Group. J Am Coll Cardiol 19: 48-54.

12. Murali S, Uretsky BF, Armitage JM, Tokarczyk TR, Betschart AR, et al. (1992) Utility of prostaglandin E1 in the pretransplantation evaluation of heart failure patients with significant pulmonary hypertension. J Heart Lung Transplant 11 716-723.

13. Kieler-Jensen N, Ricksten SE, Stenqvist O, Bergh CH, Lindelöv B, et al (1994) Inhaled nitric oxide in the evaluation of heart transplant candidates with elevated pulmonary vascular resistance. J Heart Lung Transplant 13: 366-375.

14. Givertz MM, Hare JM, Loh E, Gauthier DF, Colucci WS (1996) Effect of bolus milrinone on hemodynamic variables and pulmonary vascular resistance in patients with severe left ventricular dysfunction: a rapid test for reversibility of pulmonary hypertension. J Am Coll Cardiol 28: 1775-1780.

15. Galiè N, Ghofrani HA, Torbicki A, Barst RJ, Rubin LJ, et al. (2005) Sildenafil citrate therapy for pulmonary arterial hypertension. N Engl J Med 353: 21482157.

16. Gómez Sánchez MA, Saenz de la Calzada C, Escribano Subías P, Delgado Jiménez J, Lázaro Salvador M, et al. (2004) Pilot assessment of the response of several pulmonary hemodynamic variables to sublingual sildenafil in candidates for heart transplantation. Eur J Heart Fail 6: 615-617.

17. Shim JK, Choi YS, Oh YJ, Kim DH, Hong YW, et al. (2006) Effect of ora sildenafil citrate on intraoperative hemodynamics in patients with pulmonary hypertension undergoing valvular heart surgery. J Thorac Cardiovasc Surg 132: $1420-1425$.

18. Jabbour A, Keogh A, Hayward C, Macdonald P (2007) Chronic sildenafil lowers transpulmonary gradient and improves cardiac output allowing successful heart transplantation. Eur J Heart Fail 9: 674-677.

19. Zakliczynski M, Maruszewski M, Pyka L, Trybunia D, Nadziakiewicz P, et al. (2007) Effectiveness and safety of treatment with sildenafil for secondary pulmonary hypertension in heart transplant candidates. Transplant Proc 39 2856-2858.

20. Corbin JD, Beasley A, Blount MA, Francis SH (2005) High lung PDE5: a strong basis for treating pulmonary hypertension with PDE5 inhibitors. Biochem Biophys Res Commun 334: 930-938.

21. Nagendran J, Archer SL, Soliman D, Gurtu V, Moudgil R, et al. (2007) Phosphodiesterase type 5 is highly expressed in the hypertrophied human right ventricle, and acute inhibition of phosphodiesterase type 5 improves contractility. Circulation 116: 238-248.

22. Nagayama T, Hsu S, Zhang M, Koitabashi N, Bedja D, et al. (2009). Sildenafil stops progressive chamber, cellular, and molecular remodeling and improves calcium handling and funcition in hearts with pre-existing advanced hypertrophy caused by pressure overload. J Am Coll Cardiol 53: 207-15.

23. Delgado JF, Conde E, Sánchez V, López-Ríos F, Gómez-Sánchez MA, et al. (2005) Pulmonary vascular remodeling in pulmonary hypertension due to chronic heart failure. Eur J Heart Fail 7: 1011-1016.

This article was originally published in a special issue, Pulmonary Hypertension handled by Editor(s). Dr. Zeenat Safdar, Baylor College of Medicine, United States 